\title{
ASSESSMENT OF SALIVARY BACTERIAL LEVEL AND DENTAL CARIES EXPERIENCE IN A GROUP OF EGYPTIAN CHILDREN WITH BLACK STAINED TEETH: (A CROSS SECTIONAL STUDY)
}

\author{
Joanna Nassef William*, Hany Saber** and Norhan Eldokky ${ }^{* * *}$
}

\begin{abstract}
Aim: The purpose of this study was to assess the salivary bacterial level and dental caries experience in children with black stained teeth.

Methods: The sample comprised 73 children aged 4-6 years with black stains where the caries experience was evaluated using $\mathrm{dmft}$ index. Also, the salivary sample was taken into a sterile container and taken to the laboratory within 1 hour for processing. In the laboratory saliva dilution was done and sample was placed into a plate which contains Brain heart infusion agar. From the plate, identification of the morphology of Actinomyces was done. The colony of Actinomyces on the plate was counted with colony counter using colony forming unit. With the same salivary sample the $\mathrm{pH}$ was measured using the $\mathrm{pH}$ meter.
\end{abstract}

Results: Among the children with BS, the mean dmft was (2.3), most children had very low dmft score (42.5\%). So this showed lower caries experience in children with black stains. Regarding the Actinomyces count the results showed higher number of Actinomyces in children with BS. However it was statistically insignificant. $\mathrm{pH}$ of the studied children was mainly in the alkaline range with a mean (9.07) with prevalence $(75.2 \%)$.

Conclusion: The results of this study indicate that in this small sample of Egyptian children with black stainsthey were found to have lower caries experience. The salivary bacterial count of Actinomyces was high in the same group of children and that the higher the Actinomyces number the less the dmft score. The children with $\mathrm{BS}$ also showed $\mathrm{pH}$ mainly in the alkaline range.

KEYWORDS: Black stains, actinomyces, salivary pH, dmft score.

\footnotetext{
* Pediatric Department, Faculty of Dentistry, Cairo University, Egypt

** Associate Professor of Pediatric Dentistry and Dental Public Health Department Faculty of Dentistry, Cairo University

*** Professor of Pediatric Dentistry and Dental Public Health Department Faculty of Dentistry, Cairo University
} 


\section{INTRODUCTION}

The oral cavity plays a very important role in the protection and preservation of systemic health, it is involved in the nutritional intake and communication. The teeth are involved in all 3 roles, and dental diseases lead to multiple problems such as difficulty in swallowing, chewing or even phonetic problem. ${ }^{(1)}$

Black stains are often associated with esthetic and psychological trauma to the patient. For this reasons the patient seeks dental care. Any changes in the three distinct layers of the tooth the enamel, dentin and cementum will cause modification in the appearance of the tooth leading to a change in its light transmitting and it's reflecting properties. ${ }^{(2)}$

Black stains (BS) are type of extrinsic discoloration of the tooth. It differs in the severity, location, degree of adhesion and composition. It is characterized as dark lines or an incomplete coalescence of dark dots found mostly on cervical third of the crown and following the contour of the margin of the gingiva, which is firmly attached to the tooth surface. ${ }^{(3)}$

Slots et al., (1974) reported that chromogenic bacteria were proposed as etiological factor in production of black stains. Former study has assumed pevotella melaninogenica was related to black stains on tooth. But the most common microbiological composition of BS was found to be Actinomyces. ${ }^{(4)}$

Children with BS were found to have low caries experience in most epidemiological studies worldwide. ${ }^{(5)}$

The Aim of this study was to assess the salivary bacterial level and dental caries experience in children with black stained teeth.

\section{MATERIALS AND METHODS}

\section{Study design}

A Cross- sectional observational study.

\section{Sample size Determination:}

We applied a convenient consecutive sampling; it included all eligible children with black stain. However; considering the previous paper by Lopez Martinez, et al, 2016, the prevalence of caries in children with black stain was $5 \%$. Using a precision of 5 , a design effect set at 1 with $95 \%$ CI (confidence interval), a total sample size of 73 children with black stain recruited.The sample size was calculated by Epi info. ${ }^{(6)}$

A sample of 73 participants age 4-6 years old was randomly selected from a population that attended the Outpatient clinic of Pediatric Dentistry and Dental Public Health Department, Faculty of Dentistry, Cairo University, Egypt.

All boys and girls who met the following criteria were included in the sample (1) Patients with black stained teeth (2) primary dentition (3) cooperative children (4) medically free.

The dental caries of all patients was recorded using dental mirror and explorer. The caries experience was recorded in diagnostic chart by one examiner only using the World Health Organization (WHO) criteria for deciduous teeth and dmft caries index (sum of decayed, missed, and filled primary teeth. ${ }^{(17)}$

For the salivary sample collection the patient was asked to refrain from drinking and eating for at least 1 hour before collection of the salivary sample. (7) Patient was given a drinking bottle containing distilled water and asked to rinse their mouth well for $1 \mathrm{~min} .{ }^{(8)}$ To reduce the effect of sympathetic tone, patient was asked to sit in an upright position and relax without speaking and moving for few a minutes.${ }^{(9)}$ Five minutes after this oral rinse, patient 
was asked to spit into $15 \mathrm{ml}$ sterile calibrated tube. Put the tube on ice while collecting more saliva sample. ${ }^{(8)} 5 \mathrm{ml}$ volume of saliva was collected. Samples were taken to the laboratory within 1 hour for processing ${ }^{(10)}$

\section{In the Microbiology laboratory:}

Dilution of the saliva was done and inoculate the plates with 1 drop of diluted culture spread over the surface using a sterile bent glass rod. The sample was placed into a plate which contained brain heart infusion agar. Then the plate was inserted into an anaerobic jar and incubated in incubator with gas pack for at least 10 days at $35-37^{\circ} \mathrm{C}$. After the incubation period the colonies started to appear as a yellowish sulfer granules. The colony of Actinomyces on the plate was counted with colony counter using the colony forming unit method (CFU). ${ }^{(5)}$

\section{In the Biochemistry laboratory:}

The $\mathrm{pH}$ of the saliva was done using single electrode digital $\mathrm{pH}$ meter. The $\mathrm{pH}$ meter was calibrated every day. The $\mathrm{pH}$ meter was powered on. The probe was rinsed in distilled water and dry it with a clean, soft towel. The probe was carefully placed into a small container of the saliva and stir it briefly with the probe tip. The probe remained in the fluid sample until the digital display stabilizes. The electrode was washed with distilled water and dried with absorbent paper after each analysis. The liquids and chemicals were freshly prepared every day. ${ }^{(8)}$

\section{Statistical Analysis:}

Data was analyzed using IBM SPSS advanced statistics (Statistical Package for Social Sciences), version 24 (SPSS Inc., Chicago, IL). Numerical data was described as mean and standard deviation or median and range. Categorical data was described as numbers and percentages.

\section{RESULTS}

dmft mean was 2.3 and the minimum dmft was 0 , while the maximum dmft was 10 as presented in table (1).

- Very low dmft was the highest percentage among all classes (42.5\%), then moderate $\mathrm{dmft}$ (26\%), then low dmft (15.1\%), followed by high dmft $(12.3 \%)$ and finally very high was the lowest percentage $(4.1 \%)$.

TABLE (1): dmft of the studied children:

\begin{tabular}{|c|c|c|c|c|c|}
\hline & N & Mean & SD & Min. & Max. \\
\hline Dmft & 73 & 2.3 & 2.3 & 0 & 10 \\
\hline
\end{tabular}

N: count M: mean P: probabilitylevel

Min: minimum Max: maximum

$\mathrm{pH}$ mean of the studied children was 9.07, the lowest $\mathrm{pH}$ was 6.9 while the highest was 9.9 as presented in table (2). The $\mathrm{pH}$ range (9-9.9) was the highest range (75.2\%), then $\mathrm{pH}$ range (8-8.9) was (19.2\%), while the lowest percentage was $\mathrm{pH}$ range (6.9-7.9) as it was (5.6\%).

TABLE (2): $\mathrm{pH}$ of studied children:

\begin{tabular}{|c|c|c|c|c|c|}
\hline & $\mathrm{N}$ & Mean & SD & Min. & Max. \\
\hline $\mathrm{pH}$ & 73 & 9.07 & 0.55 & 6.9 & 9.9 \\
\hline
\end{tabular}

N: count M: mean P:probabilitylevel

Min: minimum Max: maximum

Comparison between different dmft regarding $\mathrm{pH}$ ranges was performed by chi square test which revealed in significant difference between them as $\mathrm{p}=0.1$ (insignificant in $\mathrm{P}>0.05$ ).

Mean of Salivary bacterial count of the studied children was 12.4 , the lowest salivary bacterial count was 1 while the highest was 30 as presented in table (4). The salivary bacterial count $10-20$ was the 
TABLE (3): $\mathrm{pH}$ distribution regarding dmft:

\begin{tabular}{|c|c|c|c|c|c|c|c|c|c|c|c|c|c|c|}
\hline \multirow{2}{*}{\multicolumn{2}{|c|}{$\begin{array}{l}\mathrm{pH} \text { distribution } \\
\text { among } \mathrm{dmft}\end{array}$}} & \multirow{2}{*}{$\mathrm{N}$} & \multirow{2}{*}{$\%$} & \multicolumn{2}{|c|}{ v. low } & \multicolumn{2}{|c|}{ Low } & \multicolumn{2}{|c|}{ Moderate } & \multicolumn{2}{|c|}{ High } & \multicolumn{2}{|c|}{ v. high } & \multirow{2}{*}{$\mathrm{P}$} \\
\hline & & & & $\mathrm{N}$ & $\%$ & $\mathrm{~N}$ & $\%$ & $\mathrm{~N}$ & $\%$ & $\mathrm{~N}$ & \% & $\mathrm{N}$ & $\%$ & \\
\hline \multirow{3}{*}{$\mathrm{pH}$} & $6.9-7.9$ & 4 & 5.6 & 1 & 25 & 2 & 50 & 0 & 0 & 1 & 25 & 0 & 0 & \multirow{3}{*}{0.1} \\
\hline & $8-8.9$ & 14 & 19.2 & 2 & 14.3 & 2 & 14.3 & 6 & 42.9 & 2 & 14.3 & 2 & 14.3 & \\
\hline & $9-9.9$ & 55 & 75.2 & 28 & 50.9 & 7 & 12.7 & 13 & 23.6 & 6 & 10.9 & 1 & 1.8 & \\
\hline
\end{tabular}

$N$ : count

$\%$ percentage

$P$ : probability level

highest percentage $(49.2 \%)$, then salivary bacterial count $<10$ was (34.2\%), while the lowest percentage was salivary bacterial count $>20$ as it was (17.5\%)

TABLE (4): Salivary bacterial count of the studied children

\begin{tabular}{|c|c|c|c|c|c|}
\hline & $\mathrm{N}$ & Mean & SD & Min. & Max. \\
\hline $\begin{array}{c}\text { Salivary } \\
\text { bacteria }\end{array}$ & 73 & 12.4 & 6.8 & 1 & 30 \\
\hline
\end{tabular}

N: count M: mean P: probabilitylevel

Min: minimum

Max: maximum
Comparison between different $\mathrm{dmft}$ classes regarding bacterial salivary count was performed by chi square test which revealed insignificant difference as $\mathrm{p}=0.1$ (insignificant difference $>0.05$

Correlation between salivary bacterial count and age, $\mathrm{pH} \& \mathrm{dmft}$ was detected by performing Pearson`s correlation coefficient test that revealed weak positive correlation regarding age $\& \mathrm{dmft}$ while revealed weak negative correlation with $\mathrm{pH}$.

Table (5): Salivary bacterial distribution among $\mathrm{dmft}$ :

\begin{tabular}{|c|c|c|c|c|c|c|c|c|c|c|c|c|c|c|}
\hline \multirow{2}{*}{\multicolumn{2}{|c|}{$\begin{array}{l}\text { Salivary bacteria } \\
\text { distribution among } \\
\mathrm{dmft}\end{array}$}} & \multirow{3}{*}{$\begin{array}{l}\mathrm{N} \\
25\end{array}$} & \multirow{3}{*}{$\begin{array}{c}\% \\
34.2\end{array}$} & \multicolumn{2}{|c|}{ v. low } & \multicolumn{2}{|c|}{ Low } & \multicolumn{2}{|c|}{ Moderate } & \multicolumn{2}{|c|}{ High } & \multicolumn{2}{|c|}{ v. high } & \multirow{2}{*}{$\mathrm{P}$} \\
\hline & & & & $\mathrm{N}$ & $\%$ & $\mathrm{~N}$ & $\%$ & $\mathrm{~N}$ & $\%$ & $\mathrm{~N}$ & $\%$ & $\mathrm{~N}$ & $\%$ & \\
\hline \multirow{3}{*}{$\begin{array}{l}\text { Salivary } \\
\text { bacteria }\end{array}$} & $<10$ & & & 14 & 56 & 5 & 20 & 1 & 4 & 2 & 8 & 3 & 12 & \multirow{3}{*}{0.1} \\
\hline & $10-20$ & 39 & 49.2 & 14 & 35.9 & 5 & 12.8 & 15 & 38.5 & 5 & 12.8 & 0 & 0 & \\
\hline & $>20$ & 9 & 17.5 & 3 & 33.3 & 1 & 11.1 & 3 & 33.3 & 2 & 22.2 & 0 & 0 & \\
\hline
\end{tabular}

$N$ : count

$\%$ percentage

P: probability 
TABLE (6): Correlation between Salivary bacterial count \& pH, age \& dmft:

\begin{tabular}{|c|c|c|}
\hline \multicolumn{3}{|c|}{ Salivary bacterial count } \\
\hline & $\mathbf{r}$ & P value \\
\hline Age & $0.061^{*}$ & 0.60 \\
\hline $\mathbf{p H}$ & $-0.057^{* *}$ & 0.61 \\
\hline Dmft & $0.081^{*}$ & 0.49 \\
\hline
\end{tabular}

r: Pearson's Correlation Coefficient, P-value: Probability level

*Weak positive Correlation **Weak negative Correlation

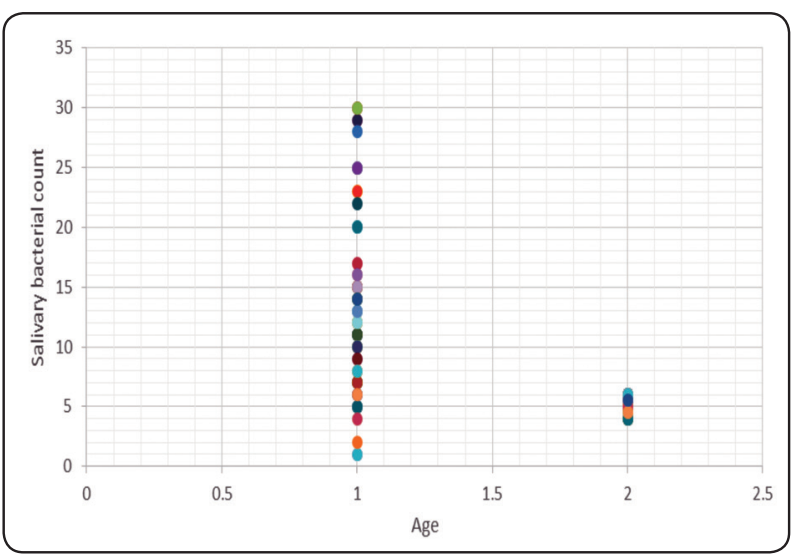

Fig. (1) Correlation between salivary bacterial count $\&$ age.

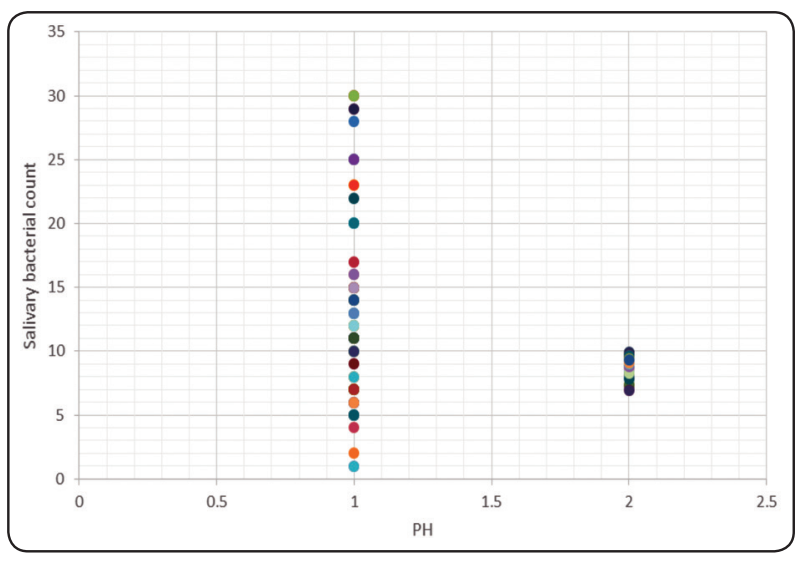

Fig. (2): Correlation between salivary bacterial count \& pH.

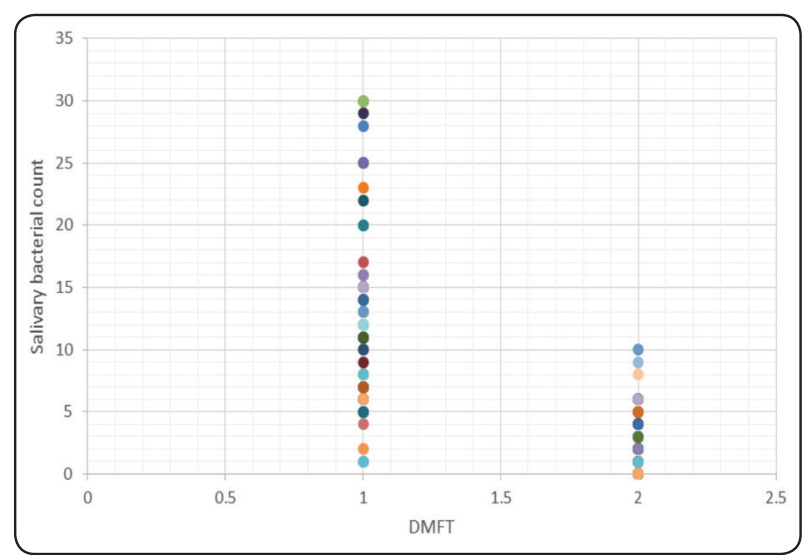

Fig. (3): Correlation between Salivary bacterial count $\& \mathrm{dmft}$

\section{DISCUSSION}

Black stains or commonly known as staining is deposit pigmentation found on the tooth surface. Lower dental caries experience has been observed in children and teenagers with the presents of black stains on dental structure. Different salivary bacteria are found in children with BS, but the most microorganism were gram-positive. The majority of these were the facilitative anaerobic rods, typically the Actinomycins. ${ }^{(11)}$

This study is an observational study that was conducted in order to assess the salivary bacterial level and dental caries in a group of children with black stained teeth. To understand the role of bacteria in pigment formation and it's relation with dental caries.

The children included are 4-6 years old with primary teeth only. This age was chosen as black stains are more common in school-age children who are in the period of primary dentition .This is due to the nature of primary teeth enamel surface that has a high permeability and porosity levels than permanent teeth and enamel thickness that is thinner. ${ }^{(5)}$

Both genders were included in the study. This was because other studies showed no correlation between sex and BS prevalence. ${ }^{(12-13)}$ 
Patients were asked to avoid drinking and eating or preforming any oral hygiene procedures for at least 1 hour before collection of the salivary sample. Collecting saliva after drinking anything will include water, dilutes saliva and reduces the amount of bacteria. In addition to diluting the sample, eating could introduce other bacteria to the sample. ${ }^{(7)}$

To reduce the effect of sympathetic tone, patients were asked to sit in an upright position and relax without speaking and moving for few a minutes. As many reports have suggested that psychological stress induce salivary alpha-amylase and cortisol levels. ${ }^{(14)}$

Samples were obtained by spitting method as during spitting more bacteria are obtained compared to the drooling method, which can affect further analysis of saliva compounds. ${ }^{(14)}$ The $\mathrm{pH}$ of the saliva was measured within 1 hour in the Biochemistry lab in order to prevent any deterioration to the sample. ${ }^{(10)}$

The bacteria chosen in this study for salivary analysis was Actinomyces. This was because former studies showed that there are significant differences in the micro flora of plaque from teeth without black stain and with black stain. In dental plaque with black stain, gram-positive rod-shaped bacteria represents $90 \%$ of the organisms in the acquired pellicle, which is a very high percentage when compared to the number of gram-positive rod-shaped bacteria found in normal dental plaque which is $35-42 \%$ of the organisms in the acquired pellicle. Gram-positive rod-shaped bacteria are the most prevalent and found in all samples. Most of the isolated microorganisms are facultative anaerobic, microaerophilic, branched, catalase negative that are characteristic of Actinomyces. ${ }^{(4)}$

The prevalence and severity of caries in childhood has been decreasing around the world. ${ }^{15}$ This was shown in the last survey in Egypt which revealed a mean dmft score of a $(3.23 \pm 4.07)$ and a prevalence of $74 \%$ in at 3-6 years of age. ${ }^{(16)}$ In our study the mean of the $\mathrm{dmft}$ score was (2.3). Most children were in very low dmft score $(42.5 \%)$.

The overall result of the present study was that children with black stains had a lower dental caries experience, when evaluating children aged 4 to 6 years. However the difference were not statistically significant.

When comparing the dmft, salivary bacteria count and $\mathrm{pH}$ with the children gender and age insignificant difference was found as other studies. ${ }^{(12-13)}$

The salivary bacterial count of Actinomyces was mostly higher range for the samples that was taken with prevalence of $(49.2 \%)$ with mean of (12.4). Previous study by Budiarjo et al., 2013 had found the relative abundance of Actinomyces was higher in children with black stain with mean $(30.87 \pm 13.30)$ compared to children without black stain with mean $(26.12 \pm 10.73) .{ }^{(5)}$ The study confirm this finding. The same study concluded that the quantity of Actinomyces on children saliva with and without BS is not statically significant, which is also in consistent with our results. This may be due to the possibility that Actinomycetes bacteria is involved in the deposition of black stains. ${ }^{(9)}$ Another reason may be that the intake of iron supplements and the regular consumption of iron rich foods could favour the development of a chromogenic microbiota. ${ }^{(13)}$ Using real-time PCR, HeinrichWeltzien et al. (2014) found no significant difference in the prevalence of A. actinomycetemcomitans and P. intermedia between black stain group and control group.

The results show that the children with higher count of Actinomyces have very low to moderate dmft score mainly. This results go in accordance with the results of the study (Yang, Zou, \& $\mathbf{L i}$, 2007) where Actinomyces spp. were detected $100 \%$ in the caries-free group, while $95 \%$ in the cariessusceptible group. $^{(18)}$ Heinrich-Weltzien et al, 2014 suggested that the significantly high level of 
Actinomycins and the tendency to lower S.mutans detected in BS samples is associated with lower caries experience. ${ }^{(17)}$ This also may be due to that these bacteria compete with the cariogenic microbiota for the location sites, which in turn reducing the potential adhesion of the cariogenic bacteria. ${ }^{(3)}$

When comparing between the different $\mathrm{dmft}$ classes regarding salivary bacterial count it reveled insignificant difference.

The $\mathrm{pH}$ of the studied children was mainly in the alkaline range with a mean (9.07) with prevalence (75.2\%). This was consistent with a study by Surdacka et al, 1989 found that the $\mathrm{pH}$ of saliva in children with staining has revealed a significantly higher $\mathrm{pH}$, compared to the control group. ${ }^{(19)}$ This may be due to the significantly high content of calcium, inorganic phosphates, copper, and sodium of children with black staining. ${ }^{(17)}$

The results of data analysis of $\mathrm{pH}$ range and $\mathrm{dmft}$ score shows that the highest $\mathrm{pH}$ range children have mainly very low dmft score. Salivary $\mathrm{pH}$ may be considered as main protective factors against dental caries. Optimum level of salivary calcium may be responsible for continuous supply of calcium to arrest the demineralization and help reduce the occurrence of dental caries. ${ }^{(20)}$ However, no statistically significant difference between the two was found.

\section{CONCLUSION}

In this small sample of Egyptian children with black stains they were found to have lower caries experience. The salivary bacterial count of Actinomyces was high in the same children. The Actinomyces count was higher with children who had low to moderate dmft score. The $\mathrm{pH}$ of the studied children was mainly in the alkaline range. The highest $\mathrm{pH}$ range children have mainly very low dmft score. Weak positive correlation between salivary bacterial count and $\mathrm{dmft}$ while weak negative with $\mathrm{pH}$ detected by preforming Pearson's correlation coefficient test.

\section{LIMITATIONS OF THE STUDY}

Although the research has reached its aims, there were some unavoidable limitations. First, because of the time limits this research was conducted only on a small size of the population who were attending the pediatric clinic at Cairo University. Second the study design was a cross sectional study. Which are therefore subjected to confounding factors that were not equally distributed among the sample and this unequal distribution may lead to bias and misinterpretation. Being open about the potential flaws may improve our perceived credibility, rather than detract from it. These limitations naturally provide direction for how future research can strengthen, improve, expand on, or verify your findings.

\section{Recommendations}

1- Conduct further epidemiological studies assessing the factors possibly involved in the phenomena of black stains and its relationship with dental caries.

2- Further studies are needed to understand the factors which give rise to extrinsic black tooth stains and the microbiological risk factors for black tooth stain.

3- Investigate the caries experience of children with and without black stain in Egyptian schools.

\section{REFERENCES}

1. Tirth, A., Bk, S., Nagarajappa, R., Tangade, P., \& Telgi, R. (2009). An Investigation into Black Tooth Stain Among School Children in Chakkar Ka Milak of Moradabad City, India. Journal of Oral Health and Community Dentistry, 3. https://doi.org/10.5005/johcd-3-2-34

2. Hegde, M., Shetty, P., \& Raksha, B. (2016). Prevalence of Anterior Teeth Discoloration in South Canara Population. Journal of Scientific Research and Reports, 10, 1-6. https://doi.org/10.9734/JSRR/2016/23040

3. Koch, M. J., Bove, M., Schroff, J., Perlea, P., Garcia-Godoy, F., \& Staehle, H. J. (2001). Black stain and dental caries in schoolchildren in Potenza, Italy. ASDC Journal of Dentistry for Children, 68(5-6), 302,353-355. 
4. Slots, J. (1974). The microflora of black stain on human primary teeth. Scandinavian Journal of Dental Research, 82(7), 484-490.

5. Indiarti I, Rustan Y, Budiarjo S. Identification Quantity of Actinomyces in Children Saliva with Black Stain in Tooth Enamel Surface. International J Clin Prev Dent. 2013;9(3):163- 8 .

6. Lopez Martinez, T. M., Goettems, M. L., Azevedo, M. S., Correa, M. B., Demarco, F. F., \& Romano, A. R. (2016). Black stains and dental caries in Brazilian schoolchildren: a cross-sectional study. Brazilian Oral Research, 30(1), e110. https://doi.org/10.1590/1807-3107BOR-2016.vol30.0110

7. Salimetrics L, SalivaBio L. Saliva Collection and Handling Advice. Salimetrics. 2015;3(3rd Edition):1-15

8. Tolentino, E. de S., Chinellato, L. E. M., \& Tarzia, O. (2011). Saliva and tongue coating $\mathrm{pH}$ before and after use of mouthwashes and relationship with parameters of halitosis. Journal of Applied Oral Science : Revista FOB, 19(2), 90-94. https:// doi.org/10.1590/s1678-77572011000200002

9. Li, Y., Zhang, Q., Zhang, F., Liu, R., Liu, H., \& Chen, F. (2015). Analysis of the Microbiota of Black Stain in the Primary Dentition. PloS One, 10(9), e0137030. https://doi. org/10.1371/journal.pone.0137030

10. Baliga, S., Muglikar, S., \& Kale, R. (2013). Salivary pH: A diagnostic biomarker. Journal of Indian Society of Periodontology, 17(4), 461-465. https://doi.org/10.4103/0972124X.118317

11. Zyla, T., Kawala, B., Antoszewska-Smith, J., Kawala, M., Żyła, T., Kawala, B., ... Kawala, M. (2015). Black Stain and Dental Caries: A Review of the Literature. BioMed Research International, 2015, 1-6. https://doi. org/10.1155/2015/469392

12. Franca-Pinto, C. C., Cenci, M. S., Correa, M. B., Romano, A. R., Peres, M. A., Peres, K. G., ... Demarco, F. F. (2012). Association between black stains and dental caries in primary teeth: findings from a Brazilian population-based birth cohort. Caries Research, 46(2), 170-176. https://doi. org/10.1159/000337280
13. Garcia Martin, J. M., Gonzalez Garcia, M., Seoane Leston, J., Llorente Pendas, S., Diaz Martin, J. J., \& Garcia-Pola, M. J. (2013). Prevalence of black stain and associated risk factors in preschool Spanish children. Pediatrics International, 55(3), 355-359. https://doi.org/doi:10.1111/ ped.12066

14. Bhattarai, K. R., Kim, H.-R., \& Chae, H.-J. (2018). Compliance with Saliva Collection Protocol in Healthy Volunteers: Strategies for Managing Risk and Errors. International Journal of Medical Sciences, 15(8), 823-831. https://doi.org/10.7150/ijms.25146

15. Bonecker, M., \& Cleaton-Jones, P. (2003). Trends in dental caries in Latin American and Caribbean 5-6- and 11-13-year-old children: a systematic review. Community Dentistry and Oral Epidemiology, 31(2), 152-157. https:// doi.org/10.1034/j.1600-0528.2003.00009.x

16. Abbass, M. M. S., Mahmoud, S. A., El Moshy, S., Rady, D., AbuBakr, N., Radwan, I. A., ... Al Jawaldeh, A. (2019). The prevalence of dental caries among Egyptian children and adolescences and its association with age, socioeconomic status, dietary habits and other risk factors. A cross-sectional study. F1000Research, 8, 8. https://doi. org/10.12688/f1000research.17047.1

17. Heinrich-Weltzien, R, Bartsch, B., \& Eick, S. (2014). Dental caries and microbiota in children with black stain and non-discoloured dental plaque. Caries Research, 48(2), 118-125. https://doi.org/10.1159/000353469

18. Yang, R., Zou, J., \& Li, J.-Y. (2007). [Study of the relationship between oral Actinomyces and childhood caries]. Hua xi kou qiang yi xue za zhi = Huaxi kouqiang yixue zazhi = West China journal of stomatology, 25(6), 568-570.

19. Surdacka A. [Chemical composition of the saliva in children and adolescents with black tartar]. Czas Stomatol. 1989;42(10-12):525-33

20. Aranibar Quiroz, E. M., Alstad, T., Campus, G., Birkhed, D., \& Lingstrom, P. (2014). Relationship between plaque $\mathrm{pH}$ and different caries-associated variables in a group of adolescents with varying caries prevalence. Caries Research, 48(2), 147-153.https://doi.org/10.1159/000355614 